\section{Survival, Growth, and Fertility of Carpinus Hybrids}

Frank S. Santamour, Jr. ${ }^{1}$

U.S. National Arboretum, Agricultural Research Service, U.S. Department of Agriculture, 3501 New York Avenue, North East, Washington, DC 20002

Additional index words. hornbeam, polyploidy, landscape trees
The need for a wider choice of small trees maturing at 10 to $13 \mathrm{~m}$ in height and capable of enduring the stressful environments of urban landscapes prompted my interest in the hornbeams (Carpinus). The first control-pollinated hybrids in Carpinus were made in 1973 and 1974 (Santamour, 1978). The chromosome numbers of the individuals used as parents were $C$. betulus L. $(2 n=8 x=64), C$. japonica Blume $(2 n=2 x=16)$, C. orientalis Mill. $(2 n=$ $2 x=16)$, C. tschonoskii Maxim. $(2 n=4 x=32)$. True hybrids, verified by chromosome counts, were obtained from $C$. orientalis $\mathrm{x} C$. tschonoskii $(2 n=3 x=24), C$. betulus $\times C$. orientalis and reciprocal $(2 n=5 x=40)$, and C. betulus $\mathrm{x} C$. tchonoskii $(2 n=6 x=48)$. No interspecific hybrids were obtained from crosses of $C$. japonica with the other three species. Sargent (1896) recognized two botanical sections in Carpinus, with $C$. japonica being classified in Sect. Distegocarpus and the other species in Sect. Eucarpinus (= Sect. Carpinus). Self-pollinations were made in all four parental species, but intraspecific crosses were limited to three species because I had only one plant of $C$. orientalis.

Seed set from selfing was extremely low, indicating a high degree of self-incompatibility in these species. Only in C. betulus were the selfed seedlings vigorous enough to grow to outplanting size in 2 to 3 years. Also, in $C$. betulus, two different intraspecific crosses gave about the same seed set, but only one cross produced seedlings.

The loss of several hybrid seedlings severely limited the numbers of plants available

Received for publication 23 Jan. 1995. Accepted for publication 18 July 1995 . The cost of publishing this paper was defrayed in part by the payment of page charges. Under postal regulations, this paper therefore must be hereby marked advertisement solely to indicate this fact.

${ }^{1}$ Research Geneticist. for long-term testing, but a representative planting was made in 1977. This planting was established on an impoverished clay soil, with virtually no topsoil, at our test site in Beltsville, Md. Spacing was $3 \mathrm{~m}$ between trees and rows, with only a modest attempt at replication within this small plot. No fertilization, watering, or other cultural practices were used, thus simulating the neglect common to many urban plantings.

The trees in this planting were measured in Nov. 1991, when the plants were 18 to 19 years old from seed (Table 1). The hybrids between C. betulus and C. tschonoskii and the intraspecific $C$. japonica progeny were outstanding in survival, growth, and adaptability to adverse site conditions. Survival of $C$. betulus, including the selfed progeny, was also high, but the trees were much slower growing and had still not reached sexual maturity when data were taken. The combination of $C$. betulus and $C$. orientalis produced trees with inferior survival and growth characteristics, and these progenies also were not sexually mature. The failure of $C$. tschonoskii to survive without repeated dieback was disappointing, because this species would have been a "new" introduction for urban landscapes. The possibility that the parents of this intraspecific progeny were siblings may have contributed to their lack of adaptability, but the selfed progeny of $C$. betulus did not exhibit signs of inbreeding depression.

Branches with elongating male catkins from the hexaploid $(2 n=48)$ trees of $C$. betulus $\times C$. tschonoskii and the sole triploid $(2 n=24)$ plant of $C$. orientalis $\times$ C. tschonoskii parentage 1992 to force pollen production. Pollen of the hexaploid averaged $37.2 \mu$ in diameter, and $95 \%$ of the grains were stainable with acetocarmine. Pollen of the triploid also appeared to be potentially functional ( $82 \%$ stained) and the grains averaged $32.4 \mu$ in diameter. Trees of $C$. japonica also were flowering but none of the $C$. betulus flowered in 1992 or 1993.

As a straight species, $C$. japonica may have some merit as a small tree for curbside plantings under telephone lines. When young, the trees are somewhat vase-shaped but become Wyman (1965), leaves of this species may exhibit a red autumn coloration in some climates. Young trees of $C$. tschonoskii have an oval crown but also become flat-topped as they mature. It will require another decade of growth before anyone can determine whether the hybrids between $C$. betulus and $C$. tschonoskii also will develop a flat-topped crown. The proven crossabilities among certain Carpinus species and the apparent fertility of the interspecific hybrids may allow advanced generation breeding if and when such work is warranted.

\section{Literature Cited}

Sargent, C.S. 1896. The sylva of North America. vol. 9. Houghton Mifflin \& Co., Boston, New York.

Santamour, F.S., Jr. 1978. Interspecific hybridization in Carpinus. Metropolitan Tree Improvement Alliance (METRIA) Proc. 1:49-56.

Wyman, D. 1965. Trees for American gardens, revised ed. Macmillan, New York. were brought into the laboratory in late Mar. flat-topped with increasing age. According to

Table 1. Survival and growth of Carpinus progenies at 18 to 19 years of age.

\begin{tabular}{|c|c|c|c|c|}
\hline \multicolumn{2}{|c|}{ Parents } & \multirow[b]{2}{*}{ Survival $^{2}$} & \multirow{2}{*}{$\begin{array}{l}\mathrm{Ht} \\
(\mathrm{m})\end{array}$} & \multirow{2}{*}{$\begin{array}{l}\text { Stem diam } \\
(\mathrm{cm})^{y}\end{array}$} \\
\hline Female & Male & & & \\
\hline$\overline{\text { C. betulus }}$ & C. tschonoskii & $9 / 9$ & 5.6 & 14.3 \\
\hline C. japonica & C. japonica & $3 / 3$ & 5.1 & 10.1 \\
\hline C. betulus & C. betulus & $6 / 6$ & 3.5 & 6.0 \\
\hline C. orientalis & C. tschonoskii & $1 / 1$ & 3.7 & 6.6 \\
\hline C. betulus & Self & $3 / 4$ & 3.4 & 5.0 \\
\hline C. betulus & C. orientalis & $2 / 7$ & 2.9 & 3.8 \\
\hline C. orientalis & C. betulus & $1 / 7$ & 2.8 & 3.5 \\
\hline C. tschonoskii & C. tschonoskii & $0 / 4$ & --- & --- \\
\hline
\end{tabular}

${ }^{2}$ Complete survival, with no dieback.

${ }^{y}$ Diameter at $30 \mathrm{~cm}$ above ground level. 